\title{
Changes in Haircut Shapes by Mixing One Length Haircut and Same Layer Haircut according to the Division of Head and Slice Lines during Hair Cutting
}

Seon-Mi Jang, Won-Ji Jung*

Department of Beauty Science, Kwangju Women's University, Gwangju, Korea

*Corresponding author: Won-Ji Jung, Department of Beauty Science, Kwangju Women's University, 69 Kwangju Yeodaegil, Gwangsan-gu, Gwangju 62396, Korea Tel.: +82629503798 Fax: +82629503797

Email: jwj65@hanmail.net

Received August 21, 2020

Revised November 11, 2020

Accepted November 25, 2020

Published December 30, 2020

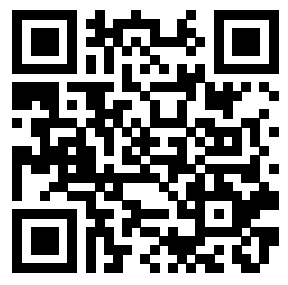

\begin{abstract}
Purpose: The goal is to provide basic data on the haircut style changes by demonstrating the changes in haircut shape and length after cutting hair by dividing head areas in three ways, applying slice lines as well as mixing one length haircut and same layer haircut. Method: After dividing the head into the front side pointgolden point (F-G), side point-golden back medium point (S-GBMP) and ear pointback point (E-B), same layer haircut is applied to the upper part and one length haircut is applied to the lower part following the slice lines of $A$ line, parallel line and V line. Result: By applying same layer haircut and one length haircut on the upper and lower part of the head respectively, haircut shapes and length of hair vary according to the dividing locations and slice lines. Conclusion: It has been demonstrated that creative haircut designs are possible when the opposite textures and shapes of different haircuts are applied to various divisions and slice lines are set following the sense of design.
\end{abstract}

Keywords: Haircut, Combination cut, One-length cut, Same layer cut, Slice lines

\section{Introduction}

현대인들의 경제 수준 향상은 미에 대한 산업을 지속적으로 변화, 발전시키고 있다(Hwang \& Youn, 2011). 미용 업은 단순한 기술직을 넘어서 전문지식을 함양하고 숙련된 기술을 사용하여 고객을 만족시 켜야 하는 대인 서비스업이다(Yeo \& Park, 2019).

헤어스타일은 이미지형성과 개성을 나타내는 중요한 수단으로써 사회적, 관계적 이미지 향상에 영향을 준다(Han \& Kim, 2019). 헤어 커트는 헤어스타일에서 토대가 되며 머리의 모양과 형태를 만드는 것 에 목적이 있다. 또한 헤어커트는 헤어스타일을 완성하는 과정에 있 어서 중추적인 역할을 한다(Ham, 2008).

헤어커트 시 커트의 형태에 변화를 줄 수 있는 절대적 요인은 시 술각도와 모발의 길이, 슬라이스 라인 그리고 베이스가 있다(Jung \& Youn, 2008). 시술각도는 모발이 두상에서 들어 올려지는 각도
를 말하며 두상시술각도와 자연시술각도로 구분된다(Jung \& Youn, 2015). 헤어커트는 모든 모발이 층이 없이 같은 선상에 떨어지는 원 랭스 커트(one-length cut)와 아래에서 위로 갈수록 층이 생기며 길 이가 길어지는 그래주에이션 커트(graduation cut), 아래에서 위로 갈 수록 길이가 같거나 짧아지며 높은 층이 나는 레이어 커트(layer cut) 로 나눌 수 있다. 이것은 시술각도로 헤어커트의 기본형을 구분한 것 이다(Kim et al., 2018a). 원랭스 커트는 슬라이스 라인에 따라서 형 태선이 변하며, 형태선에 따라 평행보브, 이사도라, 스파니엘로 나뉜 다(Lee \& Jin, 2010). 슬라이스 라인(slice line)은 블로킹(blocking) 을 더 작게 분할하여 섹션을 만드는 선을 말하며(Kim \& Lee, 2017) 섹션라인이라고도 할 수 있다. 슬라이스 라인에는 뒤쪽이 짧고 얼굴 쪽으로 갈수록 길이가 길어지는 형태의 A 라인(concave line)과 평행 의 커트형태를 만들 때 사용되는 평행라인(parallel line)이 있다. 그리 고 뒤쪽이 길고 얼굴 쪽으로 갈수록 길이가 짧아지는 형태의 $\mathrm{V}$ 라인 
(convex line)이 있다(Jung, 2011).

레이어 커트는 높은 시술각으로 인해 무게감이 없고 거칠어 보이는 커트스타일의 특징을 나타낸다. 시술각도에 따라서 세임 레이어(same layer), 인크리스 레이어(increase layer), 스퀘어 레이어(square layer) 로 분류된다(Kim et al., 2018b).

기본형에 속하는 기초 커트는 미용현장에서 단독 또는 혼합하여 사 용된다. 특히 기초커트의 혼합은 영역 분할의 위치와 종류에 따라서 고객의 두상과 얼굴형의 단점을 보완하는 동시에 고객의 요구사항을 만족시켜준다(Jang \& Jung, 2020). 또한 시술자의 감성과 독창성을 표현하기에 적합하다. 이에 여러 연구자들에 의해 두상의 분할과 기초 커트 혼합에 관한 연구가 진행되고 있다.

두상의 분할에 관한 선행 연구를 보면 Hong \& JoO (2015)가 헤어 커트 시 두상 분할을 7섹션 존으로 나누는 커트 방법이 동양인에 맞는 커트 방법이라는 것을 연구하여 보고하였다. Ha \& Youn (2019)은 헤 어커트 섹션 분할 연구를 통해 한국인의 특성에 맞는 헤어커트 기술을 개발하고 분석하였다. 남성 헤어커트의 분할에 관한 연구도 보고되었 는데, Kim \& Lee (2017)는 섹션 분할에 관한 설문을 통해 효율적인 섹 션분할 방법을 제시하였다.

헤어커트의 혼합형은 기본형의 커트 형태를 부분적으로 혼합하여 디자인하는 경우가 많으며, 고객의 취향과 신체조건에 따라 혼합되는 비율을 달리하여 디자인한다(Jeong \& So, 2008).

기초 커트의 혼합에 관한 연구를 보면 $\mathrm{Kim}$ (2015)이 그래주에이션 커트와 인크리스 레이어 커트를 혼합한 후 변화되는 헤어스타일을 연 구하였는데 섹션라인과 커트의 혼합위치 변화에 따라서 커트형태에 영향을 줄 수 있다는 것을 실증하였다. Jung \& Kim (2017)은 이사도 라 보브형 커트와 그래주에이션 커트의 혼합형스타일에 대한 연구를 실증하여 헤어커트 교육의 기초자료를 제공하였다. 또한 Kim (2016) 은 원랭스와 인크리스 레이어 커트를 중심으로 블록의 량과 모발 길 이, 섹션 라인에 따라 변화하는 헤어스타일의 형태 변화를 연구하여 보고하였다.

미용산업은 인적자원의 교육의 필요성이 절실한 분야이다(Jeong \& So, 2008). 미용사는 헤어커트에 관한 전문성과 숙련도를 가져야 하며 고객만족을 위해서 서비스교육 및 훈련에도 많은 시간과 비용투자를 해야 한다(Lee et al., 2012). 이렇게 헤어커트에도 지속적인 훈련과 교 육이 이루어짐에도 불구하고 고객의 대부분이 헤어커트 시 불만족 했 던 경험을 가지고 있으며, 고객의 불만족은 미용사들의 스트레스로 이 어지고 있다(Moon \& Lee, 2014).

미용사들은 고객의 커트불만족을 해소하기 위해서 재교육아카데 미나 기술 세미나 등의 헤어커트 교육에 지속적으로 참여하고 있다. Jung et al. (2009)은 모발 길이의 수치화가 헤어커트스타일의 과학적 입증이 가능한 것이므로 그 중요성과 필요성을 강조했다. 그러나 헤어 커트 교육기관에서는 실증으로 객관화와 수치화 된 자료가 미흡하여 미용교육생과 미용사들은 감각에 의지하여 헤어커트교육을 받는 경우 가 비일비재한 실정이다.
따라서 본 연구는 헤어커트 시 두상을 세가지 방법으로 영역을 분 할한 후에 슬라이스 라인을 적용하고 원랭스 커트와 세임 레이어 커트 를 혼합하여 커트한 후 변화되는 커트의 형태 및 길이의 변화를 실증 하여 헤어커트스타일의 변화에 관한 기초자료를 제공하고자 한다.

\section{Methods}

\section{1. 측정도구 및 방법}

1) 측정도구

본 연구에 사용된 가발은 V사(Venus, Korea)에서 판매하는 27 인 치 마네킹을 사용하였으며, 변화되는 모발의 길이를 측정하기 위해 디 지털 자(BL-DM; Bluetec, Korea)를 사용하여 측정하였다. 시술각도 측정은 베이스(base)의 중간접점에서 각도계(Starbox, Korea)를 사용 하였다. 커트 후에는 헤어 드라이기와 직경 $8 \mathrm{~cm}$ 의 롤 빗을 사용하여 커트의 형태를 변형시키지 않는 선에서 가볍게 모발의 결을 정리하였 다. 커트형태변화의 실증을 측정하기 위해 흰색 배경에 $1 \mathrm{~m}$ 의 일정한 거리에서 사진촬영 하였다. 촬영은 디지털 카메라(PL-1; Olympus, China)를 사용하였고, 앞모습과 옆모습, 뒷모습을 촬영하여 커트형태 변화를 기록하였다.

2) 측정 방법

(1) 두상의 영역분할

Center point (C.P)에서 nape point (N.P)의 정중선을 연결하고, top point (T.P)에서ear point (E.P)의 측중선을 나눠 4 등분블로킹을 하였다(Figure 1).

첫 번째 가로 분할은 양쪽 front side point (F.S.P)와 golden point (G.P)를 연결하여 분할하였으며, 분할을 기준으로 위•아래로 영역을 나누고 F-G로 명명하였다.

두 번째 가로 분할은 양쪽 side point (S.P)에서 golden back medium point (G.B.M.P)를 연결하여 분할하였으며, 분할을 기준으 로 위•아래로 영역을 나누고 S-GBMP로 명명하였다.

세 번째 가로 분할은 양쪽 ear point (E.P)와 back point (B.P)를 연결하여 분할하였으며, 분할을 기준으로 위·아래로 영역을 나누고 $\mathrm{E}-\mathrm{B}$ 로 명명하였다.

마네킹의 두상을 F-G, S-GBMP, E-B의 세가지 방법으로 분할을 하고, 상단은 over zone, 하단은 under zone으로 명명하였다(Jang \& Jung, 2020).

아래에는 원랭스 커트를 위에는 세임 레이어 커트를 적용하고 슬라 이스 라인은 $\mathrm{A}$ 라인, 평행, $\mathrm{V}$ 라인을 적용하였다.

(2) 모발 길이

모든 헤어커트의 처음 길이(guide)는 nape point (N.P)가 기준이 되 었다. Nape point의 가로, 세로 $1 \mathrm{~cm}$ 영역을 $0^{\circ}$ 를 적용하여 커트하였 

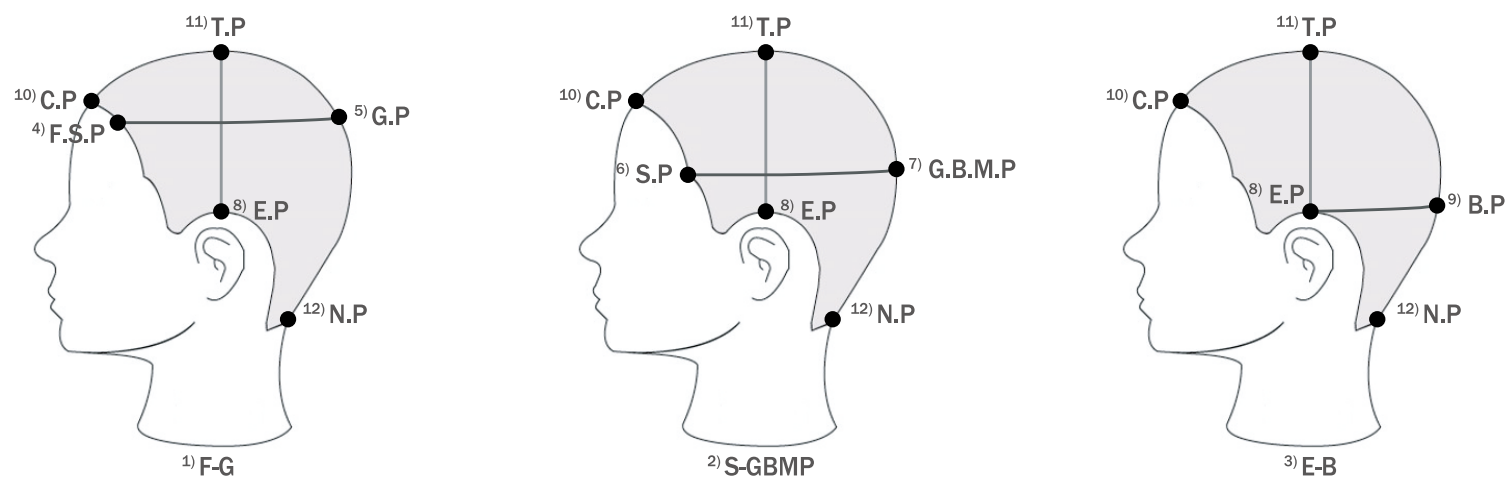

Figure 1. Segmentation of head regions.

${ }^{1} \mathrm{~F}-\mathrm{G}$, front side point-golden point; ${ }^{2}$ S-GBMP, side point -golden back medium point; ${ }^{3)} \mathrm{E}-\mathrm{B}$, ear point -back point ; ${ }^{4)} \mathrm{F} . S . P$, front side point; ${ }^{5)} \mathrm{G} . P$, golden point; ${ }^{6)}$ S.P, side point; ${ }^{7)}$ G.B.M.P, golden back medium point; ${ }^{8}$ E.P, ear point; ${ }^{9}$ B.P, back point; ${ }^{10)}$ C.P, center point; ${ }^{11)}$ T.P, top point; ${ }^{12)}$ N.P, nape point (Jang \& Jung, 2020).

다. 이때 가이드의 길이는 일정하게 $5 \mathrm{~cm}$ 로 하였다(Jung, 2011).

\section{(3) 슬라이스 라인}

슬라이스 라인은 후두부의 아래에서부터 $2 \mathrm{~cm}$ 폭으로 일정하게 나누었다.

A 라인은 back nape medium point 를 기점으로 nape side point 에서 $2 \mathrm{~cm}$ 위 지점을 전경사로 연결한 후 하단부에서부터 상단부로 이동하며 커트를 진행하였다(Jang \& Jung, 2019).

평행 라인은 nape point에서 $2 \mathrm{~cm}$ 위 지점의 위치를 평행으로 나 누고 하단부에서부터 상단부로 이동하며 커트를 진행하였다.

$\mathrm{V}$ 라인은 nape point 지점과 nape side point에서 $5 \mathrm{~cm}$ 위 지점을 후경사로 연결한 후 $2 \mathrm{~cm}$ 의 슬라이스 폭을 유지하면서 하단부에서 상단부로 이동하며 커트를 진행하였다. 단 상단부는 측두부에서부터 커트를 하였으며, 측두부에서 시작된 가이드를 연결하여 후두부상단 을 커트하였다.

\section{(4) 시술각도}

헤어커트 시에 두상 분할의 하단부에는 자연시술각 $0^{\circ}$ 의 원랭스 커트를 적용하였으며, 상단부는 두상시술각 $90^{\circ}$ 의 세임 레이어 커트 를 모든 작품에 동일하게 적용하였다.

\section{2. 헤어커트 시 두상의 분할과 슬라이스 라인에 따른 원랭스 커트 와 세임 레이어 커트 혼합의 커트형태와 길이 변화}

헤어커트 시에 두상의 분할과 슬라이스 라인에 따라 변화되는 커트 형태와 길이 변화를 실증하기 위해 두상의 영역을 $\mathrm{F}-\mathrm{G}, \mathrm{S}-\mathrm{GBMP}$, $\mathrm{E}-\mathrm{B}$ 의 세가지 방법으로 분할하였다. 분할한 후에 하단부에는 원랭스 커트를 상단부에는 세임 레이어 커트를 적용하였다.

두상을 세가지 영역별로 나눈 후 각각의 영역에 A 라인, 평행 라인, $\mathrm{V}$ 라인의 슬라이스 라인을 적용하여 헤어커트 하였다. 모든 섹션은 2 $\mathrm{cm}$ 폭으로 일정하게 나누어 아래에서 위로 커트를 하였으며, 뒤쪽에
서 앞쪽으로 커트를 진행하였다. $\mathrm{V}$ 라인은 그 특성상 상단부는 측두 부에서부터 커트를 시작하여 후두부 상단부분을 커트하였다.

모든 작품은 가이드를 $5 \mathrm{~cm}$ 로 동일하게 시작하여 블런트 커트 (blunt cut)하였다. 슬라이스 라인에 대해서 직각으로 빗질하면서 시 술각도를 적용하여 커트하였다. 커트 시술 후 변화되는 길이를 측정 하기 위해 두상에서 지점을 선정하여 일정한 방법으로 길이를 측정 하였다. 이때 선택된 지점은 nape point (이하 N.P), back point (이 하 B.P), golden back medium point (이하 G.B.M.P), golden point (이하 G.P), top point (이하 T.P), center point (이하C.P), nape side point (이하 N.S.P), ear point (이하 E.P), side corner point (이하 S.C.P)이다.

커트 후에는 헤어 드라이기와 롤 빗을 사용하여 모발의 결을 정리 하고 작품의 앞, 옆, 뒷모습을 촬영하여 커트형태의 변화를 기록하 였으며, 모든 작품에는 전개표를 작성해 커트의 과정을 제시하였다 (Jung, 2016).

\section{Results and Discussion}

\section{1. 헤어커트 시 두상의 분할과 $A$ 라인에 따른 원랭스 커트와 세임 레이어 커트 혼합의 커트형태변화}

1) 두상의 분할과 $A$ 라인에 따른 원랭스 커트와 세임 레이어 커트 혼합의 전개표

헤어커트 전개표는 미용사가 의도한 헤어디자인의 결과를 예측할 수 있는 자료가 된다. 헤어커트 시술 전 전개표를 미리 작성하여 커 트의 형태를 구상하고 설정할 수 있으며, 헤어커트를 분석할 때 분석 절차가 되기도 한다(Jung, 2016). 본 연구의 모든 작품에 헤어커트 전개표를 제시하였다.

두상을 상-하로 분할한 뒤 $\mathrm{A}$ 라인으로 나누면서 하단부에는 원랭 스 커트를 상단부에는 세임 레이어 커트를 적용하여 커트한 전개표는 
Table 1 과 같다.

전개표를 살펴보면 하단부에는 $0^{\circ}$ 의 자연시술각을 사용한 원랭스 커트 형태로 커트할 것이며, 상단부에는 $90^{\circ}$ 의 두상 시술각을 사용 한 세임 레이어 커트를 적용할 것을 나타낸다. 길이의 가이드는 $5 \mathrm{~cm}$ 이며 커트는 전경사의 방향을 적용하여 $\mathrm{A}$ 라인의 형태선을 만들 것을 나타낸다. 베이스는 슬라이스 라인과 직각으로 빗질하면서 시술각도
를 적용할 것이므로 해당사항이 없다.

2) 두상의 분할과A 라인에 따른 원랭스 커트와 세임 레이어 커트 혼합의 커트형태변화

두상의 영역을 상·하로 분할하고 $\mathrm{A}$ 라인을 만들어 상단부는 세임 레이어 커트, 하단부에는 원랭스 커트를 적용하여 커트한 작품의 결

Table 1. A planar diagram of the combination of a one-length cut and same layer cut according to head region segmentation and an A-line

\begin{tabular}{|c|c|c|}
\hline \multirow{2}{*}{ Shape } & Under & One-length cut \\
\hline & Over & Same layer cut \\
\hline Length & & N.P $5 \mathrm{~cm}$ \\
\hline Direction & & Forward slope \\
\hline Slice line & & A line \\
\hline Base & & Not applicable \\
\hline \multirow{2}{*}{ Angle } & Under & Natural angle $0^{\circ}$ \\
\hline & Over & Head angle $90^{\circ}$ \\
\hline
\end{tabular}

N.P, nape point.

Table 2. Changes in shape of the combination of a one-length cut and same layer cut according to head region segmentation and an A-line

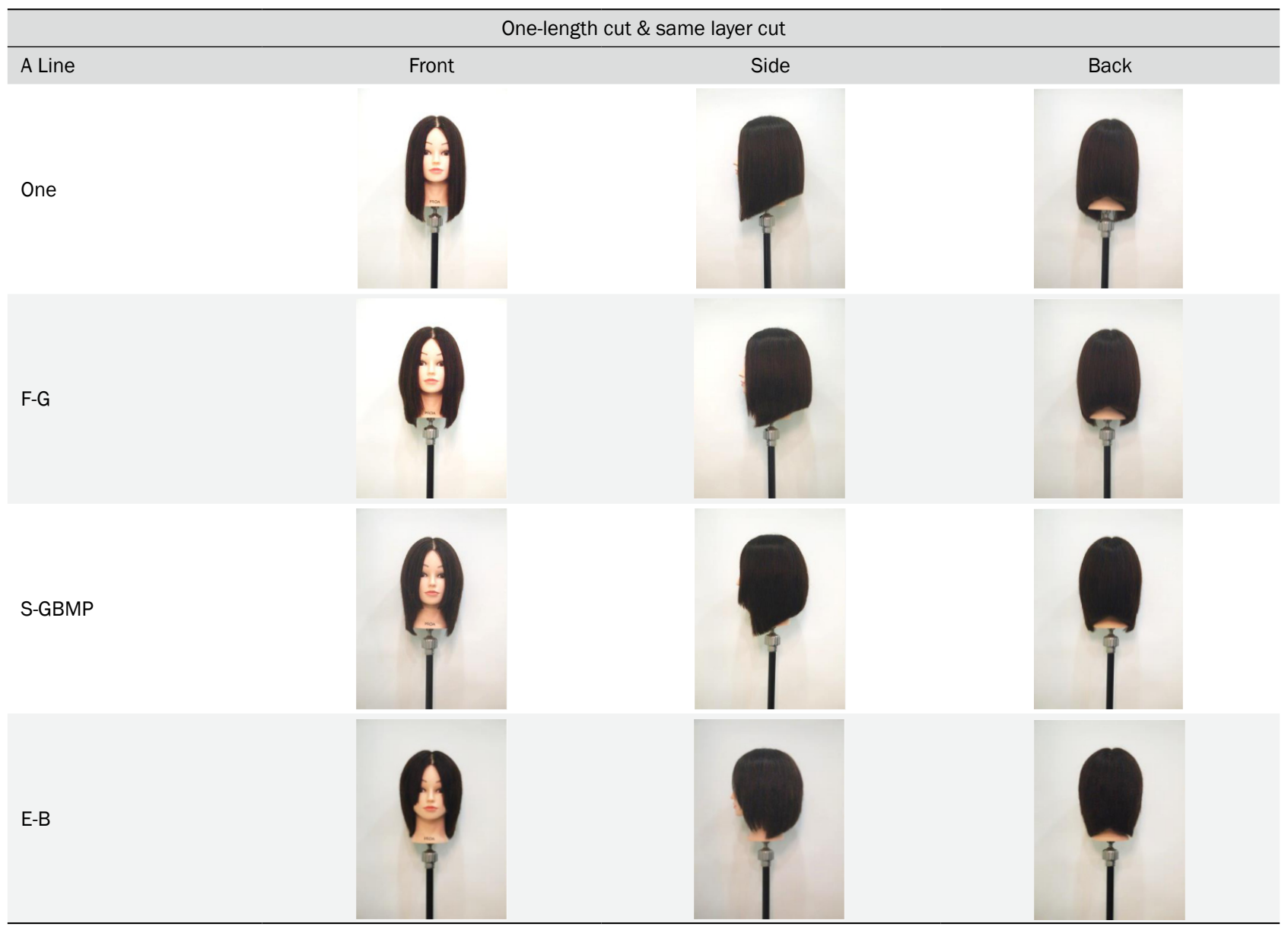

F-G, front side point-golden point; S-GBMP, side point-golden back medium point; E-B, ear point-back point; A line, concave Line; $\mathrm{V}$ line, convex line. 
과는 Table 2 와 같다.

Table 2 를 살펴보면 앞모습의 경우 상단부와 하단부의 분할의 경 계가 두드러지지 않으며 자연스럽게 층이 나타났다. 또한 $\mathrm{F}-\mathrm{G}$ 에서 $\mathrm{E}-\mathrm{B}$ 로 갈수록 커트의 형태가 세로로 긴 장방형이 되며 하단부가 가 벼워지고 거친 질감이 나타났다. $\mathrm{E}-\mathrm{B}$ 에서는 측면 영역이 없는 특성 으로 옆머리 길이가 짧아졌다.
옆모습의 경우 분할을 기준으로 상단부의 세임 레이어 커트와 하 단부에 적용된 원랭스 커트의 경계가 나타났으며 상단부에는 층이 자연스럽게 형성되어 가벼워 보이며 하단부에는 무게감이 나타났다. $\mathrm{F}-\mathrm{G}$ 와 S-GBMP에서 레이어 커트의 거친 질감과 원랭스 커트의 매 끄러운 질감이 분할을 기준으로 분명하게 나타났으나, $\mathrm{E}-\mathrm{B}$ 에서는 하단부에 적용된 원랭스 커트의 무게감이 감소되었고 레이어 커트의

Table 3. A planar diagram of the combination of a one-length cut and same layer cut according to head region segmentation and a parallel

\begin{tabular}{lcc}
\hline \multirow{2}{*}{ Shape } & Under & One-length cut \\
\cline { 2 - 3 } Length & Over & Same layer cut \\
Direction & & N.P $5 \mathrm{~cm}$ \\
Slice line & & Parallel \\
Base & Pnder & Parallel Line applicable \\
Angle & Over & Natural angle $0^{\circ}$ \\
\end{tabular}

N.P, nape point.

Table 4. Changes in shape of the combination of a one-length cut and same layer cut according to head region segmentation and a parallel

\begin{tabular}{|c|c|c|c|}
\hline \multicolumn{4}{|c|}{ One-length cut \& Same Layer cut } \\
\hline Parallel & Front & Side & Back \\
\hline One & & & \\
\hline F-G & & & \\
\hline S-GBMP & & & \\
\hline E-B & & & \\
\hline & & & \\
\hline
\end{tabular}

F-G, front side point-golden point; S-GBMP, side point-golden back medium point; E-B, ear point-back point. 
거친 질감이 드러났다. 그리고 상단부와 하단부의 경계 없이 자연스 럽게 연결되었다. N.S.P부분에는 전경사 슬라이스 라인으로 인한 날 렵한 형태선이 나타났고, 커트의 형태선에 햄 라인(hem line)의 형태 가 그대로 반영되어 나타난 것을 볼 수 있다.

뒷모습은 F-G에서 E-B로 갈수록 상단부의 레이어 커트로 인한 거 친 질감이 도드라져 나타났으며, 원랭스 커트의 무게감은 점점 줄어들 며 E-B에서는 형태선에만 무게감이 나타났다. 이러한 결과는 Jeong \& So (2008)의 기본형 커트의 혼합 비율은 형태선의 변화에 영향을 미친다는 연구결과와 일치하는 것이다.

\section{2. 헤어커트 시 두상의 분할과 평행 라인에 따른 원랭스 커트와 세 임 레이어 커트 혼합의 커트형태변화}

1) 두상의 분할과 평행 라인에 따른 원랭스 커트와 세임 레이어 커트 혼합의 전개표

Table 3은 두상을 상•하로 영역을 분할한 후 평행의 슬라이스 라인 을 적용하여 원랭스 커트와 세임 레이어 커트를 혼합하여 커트할 것임 을 나타낸다.

전개표는 두상을 상하로 분할한 뒤 상단부에는 세임 레이어 커트 를 하단부에는 원랭스 커트를 적용할 것임을 나타낸다. 길이가이드는 N.P $5 \mathrm{~cm}$ 를 기준으로, 평행의 커트 방향과 평행 라인을 적용할 것임 을 나타낸다. 시술각도는 상단부는 두상시술각 $90^{\circ}$ 를, 하단부는 자연 시술각 $0^{\circ}$ 를 사용할 것을 나타낸다.

2) 두상의 분할과 평행 라인에 따른 원랭스 커트와 세임 레이어 커트 혼합의 커트형태변화

두상을 상•하로 영역분할 한 뒤 평행의 슬라이스 라인을 적용하여 원랭스 커트와 세임 레이어 커트를 대입한 후 커트한 결과는 Table 4 와 같다.

Table 4의 앞모습을 살펴보면 F-G에서 $\mathrm{E}-\mathrm{B}$ 로 갈수록 실루엣이 점 차적으로 둥글어지는 것으로 나타났다. 이는 $90^{\circ}$ 의 레이어 커트는 둥 근 형태의 선을 만든다는 Jeong \& So (2008)의 연구와 동일한 결과이 다. 또한 $\mathrm{F}-\mathrm{G}$ 에서 $\mathrm{E}-\mathrm{B}$ 로 갈수록 하단부에 무게감은 점차 약해지며 가벼워지는 것으로 나타났다.
옆모습을 보면 F-G에서 E-B로 갈수록 실루엣이 둥글어지며 부드 러워 지는 것으로 나타났으며, 분할 지점이 매끄러우며 단차의 경계가 자연스럽게 나타났다. $\mathrm{E}-\mathrm{B}$ 는 분할 지점과 세임 레이어 커트의 특성으 로 옆머리가 층이 높아지면서 귀밑안쪽으로 모발이 말려 들어가 E.P 부분이 들뜨는 현상이 나타났다.

뒷모습의 실루엣은 둥근 형태가 되었으며 $\mathrm{F}-\mathrm{G}$ 에서 $\mathrm{E}-\mathrm{B}$ 로 갈수록 하단부에 무게감이 감소하며 거친 질감이 많이 나타났다.

전체적으로 상단부는 세임 레이어 커트로 인해 실루엣이 둥글어지 면서 볼륨이 형성되며 자연스럽게 단차가 연결되었다. 이것은 분할 지 점의 높이에 따라서 원랭스 커트의 무게감이 줄어들면서 세임 레이어 커트의 단차로 인해 두상의 골격을 그대로 나타냄과 동시에 모발의 무 게가 가벼워져 나타나는 현상으로 사료된다. 또한 단차에 의해 가벼워 진 측두부에 비해 후두부의 하단에는 무거운 느낌이 유지되었다.

\section{3. 헤어커트 시 두상의 분할과 $\mathrm{V}$ 라인에 따른 원랭스 커트와 세임 레이어 커트 혼합의 커트형태변화}

1) 두상의 영역분할과 $\vee$ 라인에 따른 원랭스 커트와 세임 레이어 커트 혼합의 전개표

Table 5는 두상을 상•하로 영역을 분할한 후 V라인의 슬라이스 라 인을 적용하여 원랭스 커트와 세임 레이어 커트를 혼합하여 커트할 것임을 나타낸다. $5 \mathrm{~cm}$ 의 길이가이드를 적용할 것이며, 후경사의 $\mathrm{V}$ 라인을 사용할 것을 계획한 것이다. 상단부는 $90^{\circ}$ 의 두상 시술각을 사용하며, 하단부는 $0^{\circ}$ 의 자연 시술각을 적용할 것임을 설정한 것이 다.

2) 두상의 분할과 $\vee$ 라인에 따른 원랭스 커트와 세임 레이어 커트 혼합의 커트형태변화

두상을 상-하로 영역분할한 뒤 $\mathrm{V}$ 라인의 슬라이스 라인을 적용 하여 원랭스 커트와 세임 레이어 커트를 대입한 후 커트한 결과를 Table 6에 나타냈다.

Table 6의 앞모습을 보면 F-G 에서 E-B로 갈수록 하단부의 무 게감은 적어지고 상단부의 가벼움이 증가하며 거친 질감이 나타났 다. 이것은 $\mathrm{V}$ 라인의 특성상 앞쪽 형태선의 길이가 짧아지며 상단부

Table 5. A planar diagram of the combination of a one-length cut and same layer cut according to head region segmentation and a V-line

\begin{tabular}{lcc}
\hline \multirow{2}{*}{ Shape } & Under & One-length cut \\
\cline { 2 - 3 } Length & Over & Same layer cut \\
Direction & & N.P $5 \mathrm{~cm}$ \\
Slice line & & Rear Slope \\
Base & & V line \\
Angle & Under & Not applicable \\
& Over & Natural angle $0^{\circ}$ \\
\hline
\end{tabular}

N.P, nape point 
는 세임 레이어 커트를 적용하고 하단부는 원랭스 커트가 적용된 결 과가 반영된 것이다. 그로 인해 $\mathrm{E}-\mathrm{B}$ 에서는 숏 커트의 형태를 보이며 후두부의 하단은 무거움이 남아 있고 세임 레이어 커트의 단차로 인 해 이마 쪽에 앞머리가 형성되었으며 전체적으로 거친 질감의 실루 엣이 나타났다.

옆모습에서는 F-G에서는 원랭스와 비슷한 무게감이 나타났으나 $\mathrm{E}-\mathrm{B}$ 로 갈수록 하단부의 무게감이 감소하는 것으로 나타났다. 그리 고 $\mathrm{F}-\mathrm{G}$ 에서 $\mathrm{E}-\mathrm{B}$ 로 갈수록 거친 질감이 도드라지게 나타났다. 상 단부는 V라인의 특성상 측면은 커트를 S.C.P위치의 측두부에서 시 작하여 후두부로 진행한 결과 상하가 연결되지 않은 디스커넥션 커 트(disconnection cut)가 형성되었다. E-B의 경우 햄 라인이 커트의 형태선에 그대로 반영되어 나타났으며, 후두부 하단은 원랭스 커트 의 무게감이 그대로 나타났다.

뒷모습에서는 하단부에 적용한 원랭스 커트의 무게감과 매끄러움 이 반영되어 나타났고, $\mathrm{F}-\mathrm{G}$ 에서 $\mathrm{E}-\mathrm{B}$ 로 갈수록 세임 레이어 커트 의 가벼움과 거친 질감이 두드러지게 나타났다. $\mathrm{F}-\mathrm{G}$ 와 S-GBMP, $\mathrm{E}-\mathrm{B}$ 모두 거친 질감과 매끄러운 질감이 극명하게 대조되었다.

\section{4. 헤어커트 시 두상의 분할과 슬라이스 라인에 따른 원랭스 커트} 와 세임 레이어 커트 혼합의 길이변화

두상을 세가지 영역으로 분할하고 $\mathrm{A}$ 라인과 평행 그리고 $\mathrm{V}$ 라인 을 적용하여 하단부에는 원랭스 커트, 상단부에는 세임 레이어 커트 를 적용하여 커트한 후 달라지는 길이변화는 Table 7에 나타내었다.

Table 7에서 A라인과 평형라인의 $\mathrm{F}-\mathrm{G}$ 에서 $\mathrm{E}-\mathrm{B}$ 까지의 B.P, G.B.M.P, G.P, T.P, C.P의 길이가 각각 지점에서 모두 동일하게 측 정된 것을 볼 수 있다. 이는 상단부에 적용한 세임 레이어 커트의 가 이드가 후두부의 정중선이기 때문이다. 정중선의 지점을 기준으로 모두 두상시술각 $90^{\circ}$ 로 온 더 베이스 커트하였기 때문에 같은 길이가 된 것이다.

$\mathrm{A}$ 라인에서 단독 커트의 경우 C.P와 T.P가 $31.0 \mathrm{~cm}$ 로 동일하게 측정되었다. 이는 C.P 와 T.P지점이 A 라인으로 연결된 한 섹션임을 나타낸다(Jang \& Jung, 2020).

평행 라인에서 단독 커트의 경우 C.P와 G.B.M.P 의 길이가 동 일하게 측정되었다. 이는 Jang \& Jung (2020)의 평행 커트의 경우 G.B.M.P와 C.P 지점이 평행 라인으로 연결된 한 섹션이라는 연구

Table 6. Changes in shape of the combination of a one-length cut and same layer cut according to head region segmentation and a V-line

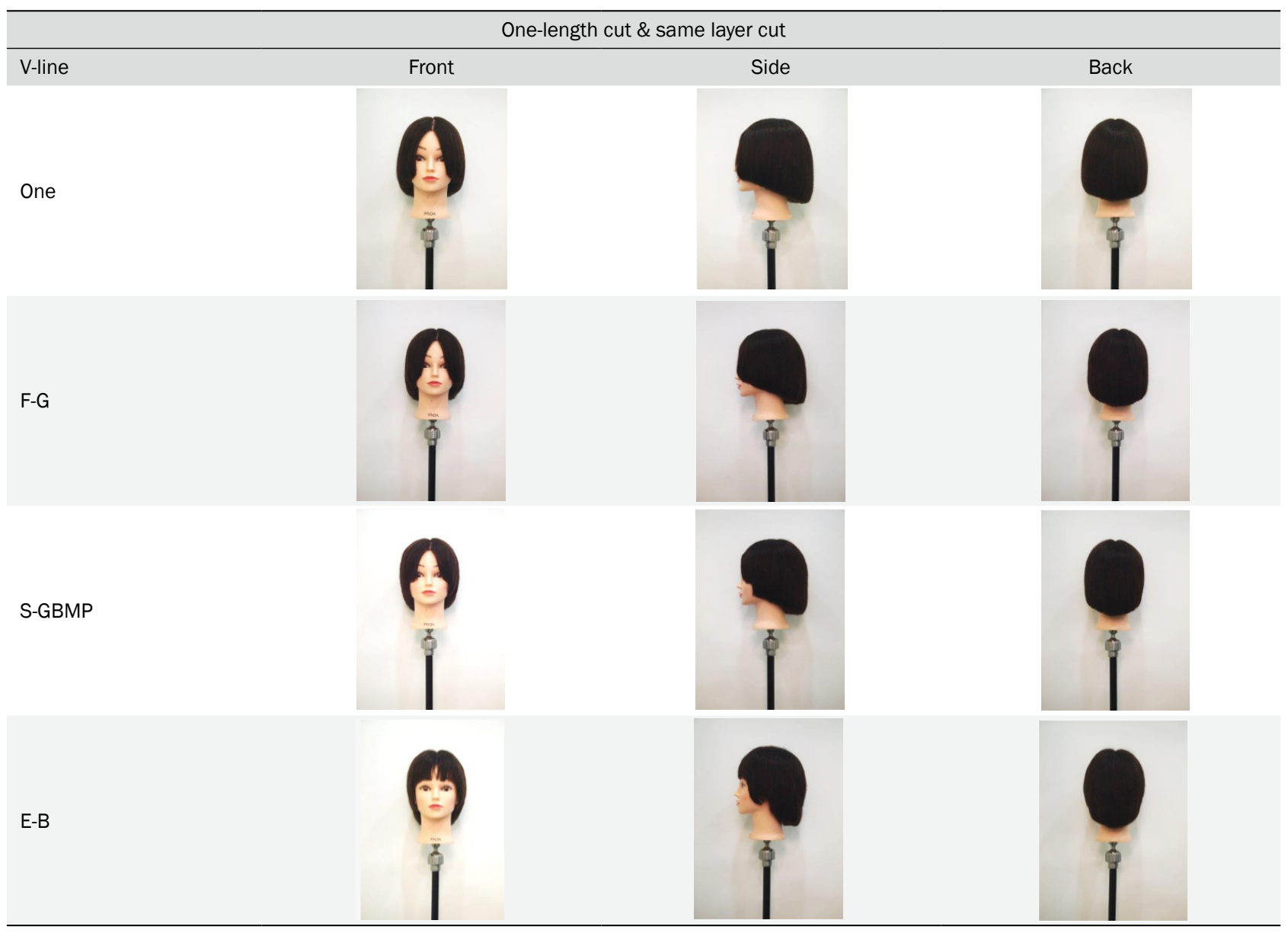

F-G, front side point-golden point; S-GBMP, side point-golden back medium point; E-B, ear point-back point; A line, concave line; $\mathrm{V}$ line, convex line. 
Table 7. Hair length changes in shape of the combination of a one-length cut and same layer cut according to head region segmentation

\begin{tabular}{|c|c|c|c|c|c|c|c|c|c|c|}
\hline Direction & & N.P & N.S.P & E.P & S.C.P & B.P & G.B.M.P & G.P & T.P & C.P \\
\hline \multirow{4}{*}{ A line } & ONE & 5.0 & 7.5 & 18.0 & 17.0 & 13.0 & 18.0 & 23.0 & 31.0 & 31.0 \\
\hline & $F-G$ & 5.0 & 7.5 & 18.0 & 17.0 & 13.0 & 18.0 & 23.0 & 23.0 & 23.0 \\
\hline & S-GBMP & 5.0 & 7.5 & 18.0 & 17.0 & 13.0 & 18.0 & 18.0 & 18.0 & 18.0 \\
\hline & E-B & 5.0 & 7.5 & 18.0 & 12.5 & 13.0 & 13.0 & 13.0 & 13.0 & 13.0 \\
\hline \multirow{4}{*}{ Parallel } & ONE & 5.0 & 5.0 & 14.0 & 13.0 & 13.0 & 18.0 & 23.0 & 27.0 & 18.5 \\
\hline & $F-G$ & 5.0 & 5.0 & 14.0 & 13.0 & 13.0 & 18.0 & 23.0 & 23.0 & 18.0 \\
\hline & S-GBMP & 5.0 & 5.0 & 14.0 & 13.0 & 13.0 & 18.0 & 18.0 & 18.0 & 18.0 \\
\hline & E-B & 5.0 & 5.0 & 13.0 & 12.5 & 13.0 & 13.0 & 13.0 & 13.0 & 13.0 \\
\hline \multirow{4}{*}{ V line } & ONE & 5.0 & 4.5 & 10.0 & 8.0 & 13.0 & 19.0 & 24.0 & 25.5 & 14.0 \\
\hline & $\mathrm{F}-\mathrm{G}$ & 5.0 & 4.5 & 10.0 & 8.0 & 13.0 & 19.0 & 12.5 & 12.5 & 12.5 \\
\hline & S-GBMP & 5.0 & 4.5 & 10.0 & 8.0 & 13.0 & 10.5 & 10.5 & 10.5 & 10.5 \\
\hline & E-B & 5.0 & 4.5 & 9.5 & 7.5 & 6.0 & 6.0 & 6.0 & 6.0 & 6.0 \\
\hline
\end{tabular}

결과와 일치하는 것이다.

$\mathrm{V}$ 라인에서 $\mathrm{F}-\mathrm{G}$ 를 보면 G.P 와 G.B.M.P에서 확연한 길이의 차 이를 볼 수 있는데, 이는 디스커넥션 커트(disconnection cut)가 되었 음을 나타내는 결과이다.

\section{Conclusion}

헤어커트 시 두상을 세가지 방법으로 영역을 분할한 후에 슬라이 스 라인을 적용하고 원랭스 커트와 세임 레이어 커트를 혼합하여 커 트한 후 변화되는 커트의 형태 및 길이의 변화를 실증하여 헤어커트 스타일의 변화에 관한 기초자료를 제공하고자 연구한 결과 다음과 같은 결론을 도출하였다.

첫째, 두상의 분할에 따른 세임 레이어 커트와 원랭스 커트의 혼 합 위치의 변화는 디자인적인 측면뿐만 아니라 얼굴형과 두상의 단 점을 보완하기에 적합하고 편리하며 동시에 고객의 요구를 만족시 킬 수 있을 것으로 사료된다. 그러므로 디자인 설계 시 분할의 위치 를 먼저 고려한 후 커트 시술에 임해야 한다는 것을 실증하였다고 할 수 있다.

둘째, 두상의 분할에 따른 세임 레이어 커트와 원랭스 커트의 혼 합을 적용 하였을 때 커트형태 차이를 이용하여 커트스타일에 롱 헤 어와 숏 헤어를 동시에 대입하여 커트하는 등 헤어디자이너의 감각 에 따른 표현이 가능한 창의적인 커트스타일을 만들어낼 수 있을 것 으로 사료된다.

셋째, 두상을 분할하여 하단부에 원랭스 커트 대입은 형태선에 무 게감을 유지하면서 상단부의 세임 레이어 커트로 질감의 역동성과 가벼움을 동시에 나타내는 커트디자인이 되었다. 이것은 원랭스 커 트와 세임 레이어 커트의 상호 장단점을 보완할 수 있으며, 더불어 세임 레이어 커트로 인한 앞머리 부분의 길이 변화는 다양한 형태의
커트디자인을 가능하게 할 것으로 사료된다.

넷째, 두상을 분할하며 적용한 슬라이스 라인에 따라서 모발 길이 의 높낮이가 달라지며 변화되는 커트형태는 고객의 얼굴형에 맞는 커트디자인과 취향 및 이미지에 따른 커트스타일을 만들어낼 수 있 을 것으로 판단된다.

이것으로 두상의 영역을 세가지 방법으로 영역을 분할한 후에 슬 라이스 라인을 적용하고 원랭스 커트와 세임 레이어 커트를 혼합하 여 커트한 후 변화되는 커트스타일에 관한 기초자료를 제공하였다. 서로 다른 커트 형태의 상반되는 질감과 형태를 다양한 분할에 대입 하고 디자인적 감각에 맞게 슬라이스 라인을 설정하였을 때 창의적 인 커트디자인이 가능하다는 것을 실증하였다.

이러한 결과는 헤어 디자이너가 고객의 신체조건과 요구에 적극 적으로 대응할 수 있고 계획적이고 창의적인 커트디자인을 만들어 내는데 필요한 기초자료가 될 수 있을 것으로 사료된다.

\section{Author's contribution}

SMJ designed, performed experiments, and wrote the manuscript. JWJ has contributed greatly to the review and writing of the manuscript.

\section{Author details}

Seon-Mi Jang (Graduate student), Department of Beauty Science, Kwangju Women's University, 69 Kwangju Yeodaegil, Gwangsan-gu, Gwangju 62396, Korea; Won-Ji Jung (Professor), Department of Beauty Science, Kwangju Women's University, 69 Kwangju Yeodae-gil, Gwangsangu, Gwangju 62396, Korea. 


\section{References}

Ha SK, Youn CS. A study on the haircut section division. Journal of the Korean Society of cosmetology, 23; 10021014, 2019.

Han MS, Kim YS. Awareness of images of women aged 20-50 years and sense of self-effectiveness through production of hair images. Asian Journal of Beauty and Cosmetology, 17: 511-520, 2019.

Ham JR. Sudy on hair design based creativity. Journal of Beauty Art Management, 2: 165-172, 2008.

Hong SH, Joo YB. 7-Section\&Zone for scalp division used in cutting hair. Journal of the Korea Society Beauty and Art, 16: 203-211, 2015.

Hwang EH, Youn CS. Factor in the beauty industry's service and returning customer satisfaction research on the impact of contact. Journal of Beauty Industry, 5: 5-20, 2011.

Jang SM, Jung WJ. Shape changes duo to the slope of the forward slope slice line in graduation haircuts. Asian Journal of Beauty and Cosmetology, 17: 211-221, 2019.

Jang SM, Jung WJ. Changes in shape of the combination of a one-length cut and a medium-graduation cut according to segmentation of head regions and slice lines. Asian Journal of Beauty and Cosmetology, 18: 221-233, 2020.

Jeong IS, So YJ. The influence of vidal sassoon and pivot point education on the style shape of haircut. Journal of the Korean Society of Cosmetology, 14: 65-73, 2008.

Jung WJ. An empirical study of the graduation cut on the basic haircut. Journal of Beauty Industry, 10: 47-62, 2016.

Jung YS, Kwon OH, Choi KH. Control technique of hair design based on haircut techniques. Journal of Investigative Cosmetology, 5: 7-13, 2009.

Jung WJ, Youn CS. Factors of form change by hair-cut. Journal of the Korean Society of Cosmetology, 14: 893-899, 2008.

Jung CS, Youn CS. Form change of cut style in relation with hair length, angle and base. Journal of Beauty Industry, 9: 53-68, 2015.

Jung WJ. Form change of hair style in relation with hair length, base, and angle in A-line hair-cut. Journal of Investigative
Cosmetology, 7: 197-205, 2011.

Jung WJ, Kim Cl. An empirical study on the mixed style of isadora bob cut and graduation cut. Journal of Beauty Industry, 11: 37-53, 2017.

Jeong IS, So YJ. The influence of vidal sassoon and pivot point education on the style shape of haircut. Journal of the Korean Society of Cosmetology, 14: 65-73, 2008.

Kim SH. A study on hair style changes by changes in the volume of hair cut blocks, hair length and section line in hair cut: focusing on one length cut and increase layered cut. Journal of the Korean Society of Cosmetology, 22: 1341-1351, 2016.

Kim SH. A study on form changes of hair styles after adjustment in hair cut section line and combination position: focusing on graduation haircut and increase layer hair cut. Journal of the Korean Society of Cosmetology, 21: 1173-1181, 2015.

Kim JS, Kang JA, Goh SH, Gwak HS, Kwon EJ, Kim MJ, Kim SW, Kim OG, Kim TY, Kim HT, et al. Basic haircut. Korea Research Institute for Vocational Education \& Training, Sejong, pp64-109, 2018a.

Kim SJ, Kim IY, Lee SH. Basic haircut. Korea Research Institute for Vocational Education \& Training, Sejong, pp47-48, 2018b.

Kim HM, Lee JS. A study on the male hair cut section division. Journal of the Korean Society of Cosmetology, 23: 811823, 2017.

Lee OH, Jin YM. A study of one-length cut by the Korean's face types. Journal of Beauty Art Management, 4: 81-90, 2010.

Lee YJ, Lee JC, Lim JK. The effects of beauty service industryemployees' job satisfaction on perception of service quality by customers. Asian Journal of Beauty and Cosmetology, 10: 79-90, 2012.

Moon SH, Lee JS. A study of dissatisfaction and complaints after hair cuts among college women. Journal of the Korea Society of Beauty and Art, 15: 135-144, 2014.

Yeo YJ, Park EJ. Emotional intelligence, customer orientation, and the organizational performance of hair salon workers. Asian Journal of Beauty and Cosmetology, 17: 199-209, 2019. 


\section{국문초록}

\section{헤어커트 시 두상의 분할과 슬라이스 라인에 따른 원랭스 커트와 세임 레이어 커트 혼합의 커트형태변화}

장선미, 정원지

광주여자대학교 미용과학과, 광주, 한국

목적: 두상을 세가지 방법으로 영역을 분할한 후에 슬라이스 라인을 적용하고 원랭스 커트와 세임 레이어 커트를 혼합하여 커트 한 후 변화되는 커트의 형태 및 길이의 변화를 실증하여 헤어커트스타일의 변화에 관한 기초자료를 제공하고자 한다. 방법: 두상을 front side point-golden point $(\mathrm{F}-\mathrm{G}$ ), side point-golden back medium point (S-GBMP), ear point-back point (E-B)로 분할한 후 $\mathrm{A}$ 라인, 평행, $\mathrm{V}$ 라인의 슬라이스 라인으로 하여 상단부는 세임 레이어 커트, 하단부는 원랭스 커트를 적용하여 헤어 커트 하였다. 결과: 두상의 분할에 상단부는 세임 레이어 커트, 하단부는 원랭스 커트를 적용하여 헤어 커트한 결과 분할의 위치와 슬라이스 라인 에 따라서 커트 형태와 모발길이의 변화가 나타났다. 결론: 서로 다른 커트 형태의 상반되는 질감과 형태를 다양한 분할에 대입하고 디자인적 감각에 맞게 슬라이스 라인을 설정하였을 때 창의적인 커트디자인이 가능하다는 것을 실증하였다.

핵심어: 헤어커트, 혼합 커트, 원랭스 커트, 세임 레이어 커트, 슬라이스 라인

\section{참고문헌}

김순희. 헤어커트의 섹션라인과 혼합위치의 변화에 따른 헤어스타일의 형태변화에 관한 연구: 그래쥬에이션 커트와 인크 리스 레이어 커트 혼합을 중심으로. 한국미용학회지, 21: 1173-1181, 2015.

김순희. 헤어커트에 있어서 커트 블럭의 량과 모발의 길이, 섹션 라인의 변화에 따른 헤어스타일의 형태 변화에 관한 연구:

원랭스 커트와 인크리스 레이어 커트를 중심으로. 한국미용학회지, 22: 1341-1351, 2016.

김진숙, 강주아, 고성현, 곽형심, 권은경, 김민정, 김서원, 김옥기, 김태영, 김현태 et al. 기초 헤어 커트. 한국직업능력개

발원, 세종시, pp64-109, 2018a.

김상진, 김인엽, 이지현. 기초헤어커트. 한국직업능력개발원, 세종시, pp47-48, $2018 \mathrm{~b}$.

김혜민, 이재숙. 남성 헤어커트 섹션 분할 연구. 한국미용학회지, 23: 811-823, 2017.

문소희, 이재숙. 여대생의 헤어 커트 시술 후 불만족과 불평행동 연구. 한국인체미용예술학회지, 15: 135-144, 2014.

여이주, 박은준. 헤어살롱 종사자의 감성지능과 고객지향성 및 조직성과의 관계. 아시안뷰티화장품학술지, 17: 199-209,

2019.

이영주, 이재철, 임재국. 미용서비스산업 종사자들의 직무만족이 고객의 서비스품질 지각에 미치는 영향. 아시안뷰티화장

품학술지, 10: 79-90, 2012.

이옥현, 진용미. 한국인 얼굴형태에 따른 원랭스 커트 연출에 대한 연구. 미용예술경영연구, 4: 81-90, 2010.

장선미, 정원지. 그래주에이션 커트의 전경사 슬라이스 라인 기울기에 따른 형태변화. 아시안뷰티화장품학술지, 17: 211-

$221,2019$.

장선미, 정원지. 두상의 영역분할과 슬라이스 라인에 따른 원랭스 커트와 미듐 그래주에이션 커트 혼합의 형태변화. 아시

안뷰티화장품학술지, 18: 221-233, 2020.

정원지, 윤천성. 헤어 커트의 形態에 變化를 주는 要因에 관한 연구. 한국미용학회지, 14: 893-899, 2008.

정원지, 윤천성. 헤어커트를 할 때 $\mathrm{V}$ 라인에서 모발길이와 각도와 베이스에 따른 커트스타일의 형태변화. 뷰티산업연구, 9 :

53-68, 2015. 
정원지. 기본헤어커트에서 그래쥬에이션 커트의 실증연구. 뷰티산업연구, 10: 47-62, 2016.

정원지. 헤어커트 시 A라인에서 모발길이와 베이스와 각도에 따른 헤어스타일의 형태변화. 대한미용학회지, 7: 197-205, 2011.

정원지, 김춘일. 이사도라 보브형 커트와 그래쥬에이션 커트의 혼합형스타일에 대한 실증연구. 뷰티산업연구, $11: 37-53$, 2017.

정윤석, 권오혁, 최근희. 커트 테크닉을 이용한 헤어디자인 조절기법. 대한미용학회지, 5: 7-13, 2009.

정인심, 소영진. 비달사순과 피봇포인트 교육이 헤어커트의 형태도출에 미친 영향. 한국미용학회지, 14: 65-73, 2008.

하성기, 윤천성. 헤어커트 섹션 분할 연구. 한국미용학회지, 25: 71-83, 2019.

한만석, 김영삼. 20-50대 여성의 이미지 인식과 헤어 이미지 연출에 따른 자기효능감. 아시안뷰티화장품학술지, 17 : 511-520,2019.

함정란. 창조성(creativity)에 의한 헤어 디자인 연구. 미용예술경영연구, 2: 165-172, 2008.

황은희, 윤천성. 미용산업의 서비스요인이 고객만족도와 재방문의도에 미치는 영향에 관한 연구. 뷰티산업연구. $5: 5-20$, 2011.

홍성희, 주연빈. 헤어 커트에 사용되는 두상 분할에 대한 7섹션 존 연구. 한국인체미용예술학회지, 16: 203-211, 2015. 


\section{中文摘要}

\section{根据头线和切片线的划分通过混合一种长度的发型和同一层的发型来改变发型}

張先美, 鄭圓至

光州女子大学美容科学科, 光州, 韩国

目的: 在以三种方式划分头部的区域之后, 应用一条切片线, 将原始的长度剪裁和相同的层剪裁混合在一起, 并 演示剪发后变化的剪裁形状和长度的变化，提供有关剪发样式变化的基本数据。方法: 将头部分为前侧黄金点 (FG) ，侧黄金点后背中点（S-GBMP）和耳点后背点（EB）之后，将上部分为 $A$ 线，平行线和V线的切片线。 通过在下端施加相同的层切和一个长度的切来切割头发。结果: 通过对头部的分割进行相同长度的剪发而在下部 进行相同长度的剪发来进行剪发, 剪发的形状和头发的长度根据分割的位置和切片线而改变。结论: 已经证明, 当用不同的切割形式的相反的纹理和形状代替各种划分并根据设计感设置切片线时，创造性的切割设计是可能 的。

关键词: 理发, 组合剪, 定尺剪, 同层剪, 切片线 